\title{
Indução de resistência por acibenzolar-S-metil em feijão caupi no controle da antracnose
}

\author{
Izabelle Taynã Dourado de Siqueira ${ }^{1}$, Lidiane Roberta $\mathrm{Cruz}^{1}$, Cristina Maria de Souza-Motta ${ }^{2}$, \\ Erika Valente de Medeiros ${ }^{1}$, Keila Aparecida Moreira ${ }^{1}$
}

${ }^{1}$ Universidade Federal Rural de Pernambuco, Unidade Acadêmica de Garanhuns, Av. Bom Pastor, s/n - Boa Vista, Garanhuns - PE, Brasil, CEP 55292-272. ${ }^{2}$ Universidade Federal de Pernambuco, Departamento de Micologia, Av. Prof. Nelson Chaves, s/n, Cidade Universitária, Recife - PE, Brasil, CEP 50670-420

Autor para correspondência: Keila Aparecida Moreira (moreirakeila@hotmail.com).

Data de chegada: 06/09/2017. Aceito para publicação em: 30/01/2018.

$10.1590 / 0100-5405 / 185029$

\section{RESUMO}

Siqueira, I.T.D.; Cruz, L.R.; Souza-Motta, C.M.; Medeiros, E.V.; Moreira, K.A. Indução de resistência por acibenzolar-S-metil em feijão caupi no controle da antracnose. Summa Phytopathologica, v.45, n.1, p.76-82, 2019.

O feijão caupi, [Vigna unguiculata (L.) Walp.] tem uma grande importância em virtude do elevado teor proteico e energético na alimentação humana. Dentre as principais doenças da cultura do feijão, destaca-se a antracnose, causada pelo desenvolvimento do fungo Colletotrichum lindemuthianum. A indução de resistência torna-se uma alternativa para controle desse micro-organismo, entre os indutores mais utilizados, destaca-se o acibenzolar-S-metil (ASM). Dessa forma, o presente trabalho teve como objetivo avaliar a eficiência do ASM em feijão caupi no controle da antracnose, causada pelo fungo Colletotrichum lindemuthianum URM 5771, bem como a ativação de enzimas relacionadas à patogenicidade. O estudo foi conduzido em casa de vegetação e os tratamentos foram dispostos em um esquema de delineamento inteiramente casualizado, sendo cinco tratamentos (Tratamento $1-0,15 \mathrm{~g} \mathrm{~L}^{-1}$; Tratamento 2 - 0,30 $\mathrm{g} \mathrm{L}^{-1}$; Tratamento $3-0,45 \mathrm{~g} \mathrm{~L}^{-1}$ e Tratamento $4-0,60 \mathrm{~g} \mathrm{~L}^{-1}$ ), incluindo o controle (apenas água) e quatro repetições. Os tratamentos com maiores doses do ASM proporcionaram maior atividade enzimática e consequentemente maior resistência às plantas de feijão caupi.

Palavras-chave: Colletotrichum lindemuthianum, feijoeiro, peroxidase, catalase, polifenoloxidase, ascorbato peroxidase.

\section{ABSTRACT}

Siqueira, I.T.D.; Cruz, L.R.; Souza-Motta, C.M.; Medeiros, E.V.; Moreira, K.A. Induction of acibenzolar-S-methyl resistance in cowpea to control anthracnose. Summa Phytopathologica, v.45, n.1, p.76-82, 2019.

Cowpea [Vigna unguiculata (L.) Walp.] is of great importance due to its high protein and energy content for human diet. Among the major diseases of bean culture is anthracnose, caused by the development of the fungus Colletotrichum lindemuthianum. Resistance induction becomes an alternative to control this microorganism; among the most commonly used inducers is acibenzolar-Smethyl (ASM). Thus, the present study aimed to evaluate ASM efficiency in controlling anthracnose in cowpea, which is caused by the fungus Colletotrichum lindemuthianum URM 5771, as well as the activation of enzymes related to its pathogenicity. The study was conducted in a greenhouse and treatments were arranged in a completely randomized design, constituting 5 treatments (Treatment $1-0.15 \mathrm{~g} \mathrm{~L}^{-1}$; Treatment $2-0.30 \mathrm{~g} \mathrm{~L}^{-1}$; Treatment $3-0.45 \mathrm{~g} \mathrm{~L}^{-1}$ and Treatment $4-0.60 \mathrm{~g} \mathrm{~L}^{-1}$ ), including control (water only) and four replicates. Treatments with higher ASM levels provided higher enzymatic activity and, consequently, greater resistance to cowpea plants.

Keywords: Colletotrichum lindemuthianum, common bean plant, peroxidase, catalase, polyphenol oxidase, ascorbate peroxidase.

O feijoeiro [Vigna unguiculata (L.) Walp)], também conhecido como feijão macassar, feijão caupi ou feijão de corda, é uma leguminosa de grande importância ao consumo humano, pois é rica em proteínas e aminoácidos, e também pode ser utilizada para diversificação de renda nas propriedades rurais (22). É uma cultura de grande relevância socioeconômica, notadamente em razão da grande quantidade de mão de obra que o seu cultivo demanda gerando diversos empregos diretos e indiretos (19).

A antracnose é a principal doença da cultura do feijão, podendo promover perdas totais em combinações de cultivar susceptível e clima favorável ao desenvolvimento do fungo agente causal. Sob condições favoráveis, pode causar danos de até $100 \%$ (2).

A alta variabilidade patogênica do fungo Colletotrichum lindemuthianum (Sacc. \& Magnus) tem sido detectada em muitas áreas das Américas, criando assim dificuldades para a incorporação de uma resistência duradoura do feijão, já que esta variabilidade nestas áreas aumenta (2). Para invadir o tecido hospedeiro, as espécies de
Colletotrichum utilizam estratégias que variam de hemibiotróficos intracelular a necrotróficos subcuticular, desenvolvendo estruturas especializadas para penetrar no hospedeiro. Com o processo de colonização do patógeno, nos tecidos da planta afetada, surgem os sintomas de antracnose, visíveis em folhas, inflorescências e frutos, sendo a doença mais severa em regiões tropicais e subtropicais (15).

Os sintomas da antracnose podem ser observados em todas as partes da planta: nas plântulas as lesões dos cotilédones são pequenas de coloração marrom ou preta e no hipocótilo apresentam lesões alongadas, superficiais ou deprimidas podendo levar a morte da plântula; as folhas apresentam sintomas nas nervuras com lesões necróticas de coloração marrom-escura na face inferior. As lesões no caule nos pecíolos são alongadas, escuras e às vezes deprimidas, já na vagem são geralmente circulares e deprimidas de coloração de marrom, com os bordos escuros e salientes, circundados por um anel pardo-avermelhado (27).

A demanda pelo uso sistemático de fungicidas, além de aumentar os custos, ainda pode selecionar espécies de patógenos resistentes, quando 
utilizado de forma inadequada, dificultando ainda mais o manejo da doença. Além disso, não existen fungicidas registrados no Ministério da Agricultura para a cultura do feijão caupi. A utilização da indução de resistência torna-se uma alternativa a esta prática, pois, ativa os mecanismos latentes de resistência da planta com o uso de agentes bióticos ou abióticos. Entre os indutores, destaca-se o acibenzolar-Smetil (24) um indutor de resistência que não possui ação antimicrobiana direta, mas interfere nos processos físiológicos e/ou bioquímicos das plantas, como a produção de fenóis, ativando a resistência sistêmica $(7,21)$.

O presente trabalho teve como objetivo avaliar a eficiência do acibenzolar-S-metil em feijão caupi no controle da antracnose, causada pelo fungo Colletotrichum lindemuthianum URM 5771, bem como a ativação de enzimas relacionadas à patogenicidade.

\section{MATERIAL E MÉTODOS}

O estudo foi conduzido em casa de vegetação, no município de Garanhuns - PE, agreste meridional, localizado sob as coordenadas geográficas: $08^{\circ} 53$ '25" de latitude $\mathrm{S}$ e $36^{\circ} 29^{\prime} 34^{\prime \prime}$ de longitude $\mathrm{O}$, com altitude média de $896 \mathrm{~m}$. O clima da região é classificado como Tropical de Altitude tipo Csa, com temperatura média anual de $20,6{ }^{\circ} \mathrm{C}$ e precipitação média em torno de $1.300 \mathrm{~mm}$. Sementes de feijão da cultivar IPA 206, de ciclo precoce e susceptível a antracnose, foram fornecidas pelo Instituto Agronômico de Pernambuco (IPA), e cultivadas em vasos de $4 \mathrm{~L}$, contendo mistura de solo, areia e matéria orgânica (húmus) (2:1:2) e mantidos em casa de vegetação, regados uma vez ao dia, durante trinta e dois dias.

Quatro sementes foram semeadas em cada vaso, com a germinação ocorrendo ao $5^{\circ}$ dia após a semeadura. Os tratamentos foram dispostos em um delineamento inteiramente casualizado, o indutor acibenzolarS-metil foi aplicado pulverizando-se $10 \mathrm{~mL}$ de solução por planta, em quatro diferentes concentrações, organizados desta forma em quatro tratamentos (Tratamento $1-0,15 \mathrm{~g} \mathrm{~L}^{-1}$; Tratamento 2 - 0,30g L $\mathrm{L}^{-1}$; Tratamento 3 - 0,45g L $\mathrm{L}^{-1}$; Tratamento $4-0,60 \mathrm{~g} \mathrm{~L}^{-1}$ ) e água destilada como o controle negativo, com 4 repetições e 3 coletas realizadas em plantas diferentes para avaliação da doença. Ao $18^{\circ}$ dia após a emergência, quando já havia 2 folhas, procedeu-se a pulverização com as diferentes doses do indutor e água destilada (controle). Dois dias após o tratamento com o indutor de resistência, quando as plantas apresentavam três pares de folhas formadas, foi inoculado Colletotrichum lindemuthianum URM 5771, na concentração de $7,6 \times 10^{6}$ conídios por $\mathrm{mL}$. As plantas foram mantidas cobertas com sacos plásticos durante 4 dias para favorecer o desenvolvimento do fungo. Foram realizadas coletas ao $24^{\circ}, 28^{\circ}$ e $32^{\circ}$ após a emergência (4, 8 e 12 dias após a inoculação) para posterior determinação das atividades enzimáticas.

Para realização das determinações analíticas, em cada amostragem, 1 par de folhas do feijoeiro completamente formada foi coletada de cada tratamento e rapidamente armazenadas em freezer $\left(-20^{\circ} \mathrm{C}\right)$. Amostras congeladas das folhas foram pesadas $(0,1 \mathrm{~g})$ e maceradas com $\mathrm{N}_{2}$ líquido em almofariz com adição de polivinilpirrolidona $1 \%$ $(\mathrm{p} / \mathrm{v})$ até a obtenção de um pó fino que em seguida foi homogeneizado em solução tampão fosfato de sódio $50 \mathrm{mM}, \mathrm{pH}$ 7,0 e, posteriormente centrifugado a $10.000 \times g$ por $10 \min$ a $4{ }^{\circ} \mathrm{C}$ e o sobrenadante utilizado para as determinações enzimáticas (1).

A peroxidase foi determinada a $30{ }^{\circ} \mathrm{C}$, por método espectrofotométrico direto, pela avaliação da conversão do guaiacol em tetraguaiacol a $470 \mathrm{~nm}$ (12), a mistura reacional continha $2,5 \mathrm{~mL}$ da solução com $135 \mu \mathrm{L}$ de guaiacol, $50 \mu \mathrm{L}$ de peróxido de hidrogênio e $50 \mu \mathrm{L}$ do extrato proteico. A atividade foi expressa em $\mu \mathrm{mol} \mathrm{H}_{2} \mathrm{O}_{2}$ decomposto $\min ^{-1} \mathrm{~g}^{-1} \mathrm{MF}$, com leitura da absorbância no tempo $0 \mathrm{e}^{2}$ após 60 segundos, realizadas em quintuplicatas para cada tratamento. Para a determinação da catalase foi utilizado EDTA $(1 \mathrm{mM})$, peróxido de hidrogênio $100 \mathrm{mM}$, dissolvido em solução tampão fosfato de potássio $50 \mathrm{mM}(\mathrm{pH} 6,0)$. A mistura reacional continha $1390 \mu \mathrm{L}$ de solução tampão, $50 \mu \mathrm{L}$ do extrato enzimático, $60 \mu \mathrm{L}$ de peróxido de hidrogênio. As leituras em espectrofotômetro foram realizadas a 240 $\mathrm{nm}$, no tempo 0 e após 60 segundos e os resultados foram expressos em $\mu \mathrm{mol} \mathrm{H}_{2} \mathrm{O}_{2}$ decomposto $\min ^{-1} \mathrm{~g}^{-1} \mathrm{MF}$, em quintuplicatas para cada tratamento. Enquanto que para a determinação da atividade da polifenoloxidase (PFO) foi determinada segundo a metodologia de Kar e Mishra (9). O substrato foi composto por pirogalol, na concentração de $50 \mathrm{mM}$, dissolvido em solução tampão fosfato de sódio $100 \mathrm{mM}$ (pH 6,8). A reação foi composta por $1 \mathrm{~mL}$ de pirogalol, $25 \mu \mathrm{L}$ do extrato enzimático, após cinco minutos interrompeu-se a reação com a adição de $25 \mu \mathrm{L}$ de ácido sulfúrico (5\%). As leituras em espectrofotômetro foram realizadas a $420 \mathrm{~nm}$ e os resultados expressos em $\mu$ mol de $\mathrm{H}_{2} \mathrm{O}_{2}$ decomposto $\min ^{-1} \mathrm{~g}^{-1}$ MF. Para a atividade de ascorbato peroxidase foi determinada usando-se EDTA $(1 \mathrm{mM})$, peróxido de hidrogênio $100 \mathrm{mM}$, e ácido ascórbico, solubilizado em solução tampão fosfato de potássio $50 \mathrm{mM}(\mathrm{pH} \mathrm{6,0).} \mathrm{A} \mathrm{reação} \mathrm{se} \mathrm{desenvolveu} \mathrm{misturando-se}$ $1335 \mu \mathrm{L}$ de tampão, $75 \mu \mathrm{L}$ do extrato enzimático, $75 \mu \mathrm{L}$ de ascorbato e $15 \mu \mathrm{L}$ de peróxido de hidrogênio, lida em espectrofotômetro a 290 $\mathrm{nm}$, no tempo 0 e após 60 segundos. Os resultados foram expressos em $\mu \mathrm{mol}$ de $\mathrm{H}_{2} \mathrm{O}_{2}$ decomposto $\mathrm{min}^{-1} \mathrm{~g}^{-1} \mathrm{MF}$. As leituras foram realizadas em cinco amostras de cada tratamento.

A severidade da antracnose foi avaliada 12 dias após a inoculação do micro-organismo, utilizando-se a escala de notas de Rava et al. (17) que varia de 1 a 9, sendo: 1 = ausência de sintomas; 2 = até $1 \%$ das nervuras apresentando machas necróticas, perceptíveis somente na face inferior da folha; 3 = maior frequência dos sintomas foliares descritos no grau 2 , até $3 \%$ das nervuras afetadas; $4=$ até $1 \%$ das nervuras apresentando manchas necróticas, perceptíveis em ambas as faces da folha; 5 = maior frequência dos sintomas foliares descritos no grau 4 , até 3\% das nervuras afetadas; $6=$ manchas necróticas nas nervuras, perceptíveis em ambas as faces da folha, presença de algumas lesões nos talos, ramos e pecíolos; 7 = manchas necróticas na maioria das nervuras, com grande parte do tecido do mesófilo adjacente rompendo-se e presença abundante de lesões nos talos, ramos e pecíolos; $8=$ manchas necróticas quase na totalidade das nervuras, ocasionando rompimento, desfolha, e redução do crescimento das plantas, assim como lesões muito abundantes nos talos, ramos e pecíolos; 9 = maioria das plantas mortas. Em seguida, as notas foram transformadas em porcentagem de área foliar afetada (14).

Todos os resultados obtidos foram submetidos à análise de variância e a comparação de médias pelo teste de Tukey, a 5\% de probabilidade. Foi realizada, ainda, análise de regressão e os gráficos obtidos no programa Excel, versão 2007-2010 e para a análise estatística foi utilizado o programa SISVAR.

\section{RESULTADOS E DISCUSSÃO}

A severidade da antracnose em feijão caupi foi maior, considerada baixa quando comparada a pressão do inóculo, no quarto dia após a inoculação quando se aplicou apenas água nas plantas (Tabela 1). No 
oitavo dia após a inoculação a severidade da doença apresentou redução quando as plantas foram submetidas a uma maior dose de indutor $\left(0,45 \mathrm{~g} \mathrm{~L}^{-1}\right)$ quando comparada ao controle. No décimo segundo dia após a inoculação a severidade da doença apresentou redução quando as plantas foram submetidas a aplicação com $0,45 \mathrm{~g} \mathrm{~L}^{-1}$ e $0,60 \mathrm{~g} \mathrm{~L}^{-1}$ do indutor.

Tabela 1. Severidade (\%) da antracnose em plantas de feijão caupi cultivar IPA 206 tratadas com diferentes doses de acibenzolar-S-metil.

\begin{tabular}{cccc}
\hline & \multicolumn{3}{c}{ Dias após inoculação } \\
\hline Tratamento & $\mathbf{4}$ & $\mathbf{8}$ & $\mathbf{1 2}$ \\
Controle & $0,76 \mathrm{~d}$ & $0,65 \mathrm{a}$ & $0,70 \mathrm{c}$ \\
$\mathrm{T} 1\left(0,15 \mathrm{~g} \mathrm{~L}^{-1}\right)$ & $0,10 \mathrm{a}$ & $0,70 \mathrm{a}$ & $0,96 \mathrm{a}$ \\
$\mathrm{T} 2\left(0,30 \mathrm{~g} \mathrm{~L}^{-1}\right)$ & $0,43 \mathrm{~b}$ & $0,45 \mathrm{~b}$ & $0,76 \mathrm{~b}$ \\
$\mathrm{~T} 3\left(0,45 \mathrm{~g} \mathrm{~L}^{-1}\right)$ & $0,30 \mathrm{c}$ & $0,30 \mathrm{c}$ & $0,61 \mathrm{c}$ \\
$\mathrm{T} 4\left(0,60 \mathrm{~g} \mathrm{~L}^{-1}\right)$ & $0,38 \mathrm{~b}$ & $0,31 \mathrm{c}$ & $0,66 \mathrm{c}$ \\
\hline $\mathrm{CV}(\%)$ & 45,56 & 42,84 & 41,98
\end{tabular}

Médias seguidas da mesma letra na coluna não diferem, estatisticamente, pelo teste de Tukey ao nível de 5\% de probabilidade.

Na Figura 1 pode-se observar que ocorreu um aumento da atividade da peroxidase no oitavo dia após a inoculação do indutor na concentração $0,45 \mathrm{~g} \mathrm{~L}^{-1}$ (Tratamento 3 ). Ao décimo segundo dia após a inoculação houve aumento da atividade quando se aplicou $0,45 \mathrm{~g} \mathrm{~L}^{-1} \mathrm{de}$ indutor de resistência e um aumento quando se aplicou a menor dose do indutor $\left(0,15 \mathrm{~g} \mathrm{~L}^{-1}\right)$.

As respostas das plantas aos estresses abióticos ou bióticos envolvem mecanismos de defesa pré-formados ou pós-formados, em sucessivos eventos e sinais, desde o reconhecimento do agressor até a ativação das barreiras físicas e químicas de defesa. Neste processo não há qualquer alteração no genoma do vegetal, ocorrendo apenas a ativação de mecanismos latentes, frente a indutores externos (23). Dentre estes mecanismos, destaca-se a ativação de enzimas que permitem acompanhar o estado de indução de resistência em plantas expostas a patógenos (13).

A peroxidase desempenha um papel importante durante o mecanismo de defesa induzida em plantas, sendo correlacionadas com a resposta de resistência ou susceptibilidade em diferentes interações patógeno-hospedeiro (18). Esta enzima é responsável pela remoção de átomos de hidrogênio dos grupos álcoois hidroxicinâmicos, cujos radicais se polimerizam para formar a lignina. Esse polímero, juntamente com a celulose e outros polissacarídeos que ocorrem na parede celular das plantas superiores, funciona como uma barreira física à penetração do patógeno. Além disso, esta enzima também participa da biossíntese do etileno, e na oxidação de ácido indol acético (AIA) e de compostos fenólicos (4).

No presente estudo, pode-se observar aumento gradativo da atividade da peroxidase, concomitantemente ao aumento da concentração do indutor, sugerindo aumento da resistência induzida. Este tipo de indução em conjunto com outras medidas de controle, tradicionalmente utilizadas, compõe um adequado manejo, focalizando a redução de custos e perdas ocasionadas por patógenos.

Campos et al. (3) constataram que atividade da peroxidase elevada, pode indicar aumento na biossíntese de lignina, que atua como uma barreira à infecção microbiana e também pode promover aumentos na concentração de produtos de oxidação de fenólicos. A peroxidase ainda possui grande afinidade por substratos envolvidos na lignificação da parede celular e os produtos da sua atividade também possuem atividade antimicrobiana direta na presença de peróxido de hidrogênio (1).

A determinação da catalase avaliada a partir de folhas de feijão caupi está representada pela Figura 2. Pode-se verificar aumento na atividade enzimática no tratamento controle no oitavo dia após a inoculação.

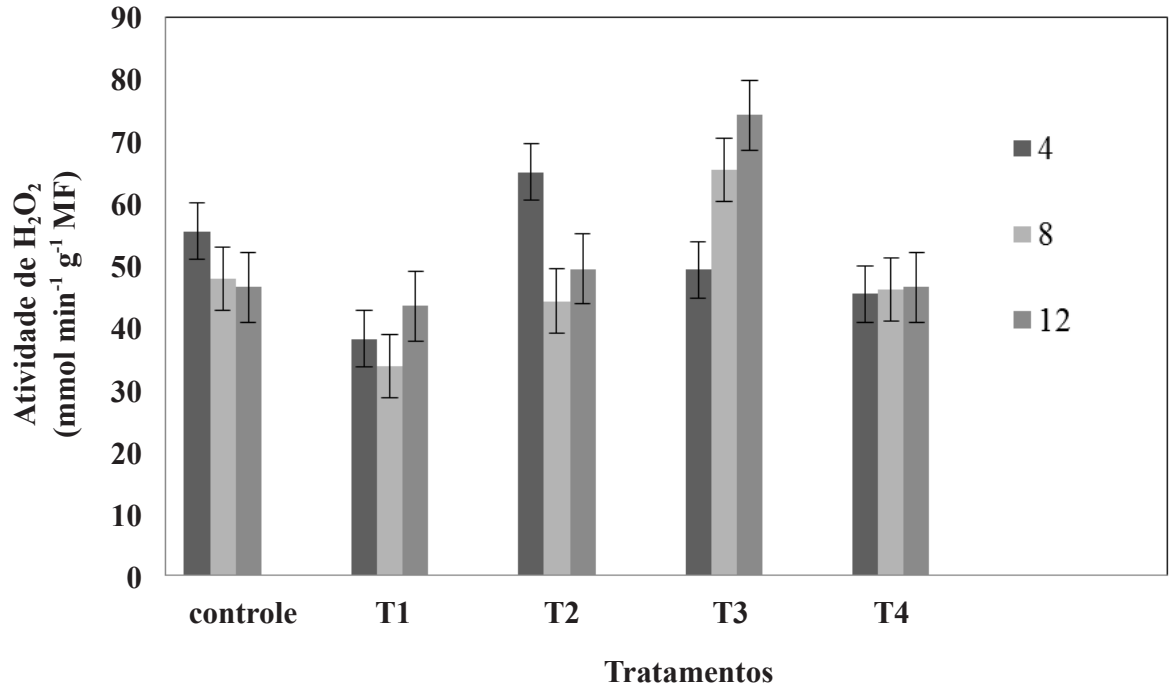

Figura 1. Atividade da peroxidase em folhas de feijão caupi, cultivar IPA 206, nos diferentes tempos (dias) de inoculação com Colletotrichum lindemuthianum URM 5771 e acibenzolar-S-metil. Tratamentos: T1 $\left(0,15 \mathrm{~g} \mathrm{~L}^{-1}\right)$; T $2\left(0,30 \mathrm{~g} \mathrm{~L}^{-1}\right)$; T $3\left(0,45 \mathrm{~g} \mathrm{~L}^{-1}\right)$, T $4\left(0,60 \mathrm{~g} \mathrm{~L}^{-1}\right)$ e controle (água destilada). 
Somente a partir do décimo segundo dia após a inoculação ocorreu aumento da atividade nos tratamentos 1 e 2 .

Durante a interação patógeno-hospedeiro ocorre a ativação do sistema de defesa da planta por vários meios, resultando na produção de substâncias tóxicas aos patógenos, impedindo o estabelecimento destes. Alguns compostos produzidos pelas plantas possuem ação antimicrobiana, enquanto outros restringem o desenvolvimento de patógenos pela formação de barreiras estruturais (28). A resistência sistêmica adquirida (RSA), caracteriza-se pela expressão de genes relacionados com a produção de proteínas PR (incluídas com a patogênese), consideradas como importantes fatores na resistência de plantas a diversas classes de fitopatógenos, incluindo fungos, bactérias, vírus e oomicetos (29).

Segundo Deuner et al. (7) a redução da atividade de catalase ocasiona um excessivo estresse causado pelo ataque de um fitopatógeno. Quando essa enzima não atua de forma eficiente, a peroxidação lipídica se torna mais evidente, sendo este o principal sintoma atribuído ao dano oxidativo, frequentemente utilizada como um indicador de dano as membranas celulares. Valente (25) avaliou a atividade de catalase e os mecanismos de defesa em mudas de cafeeiro, utilizando indutores de resistência, obtidos de extratos vegetais frente à patógenos. $\mathrm{O}$ aumento da atividade de enzimas antioxidantes como a catalase pode traduzir

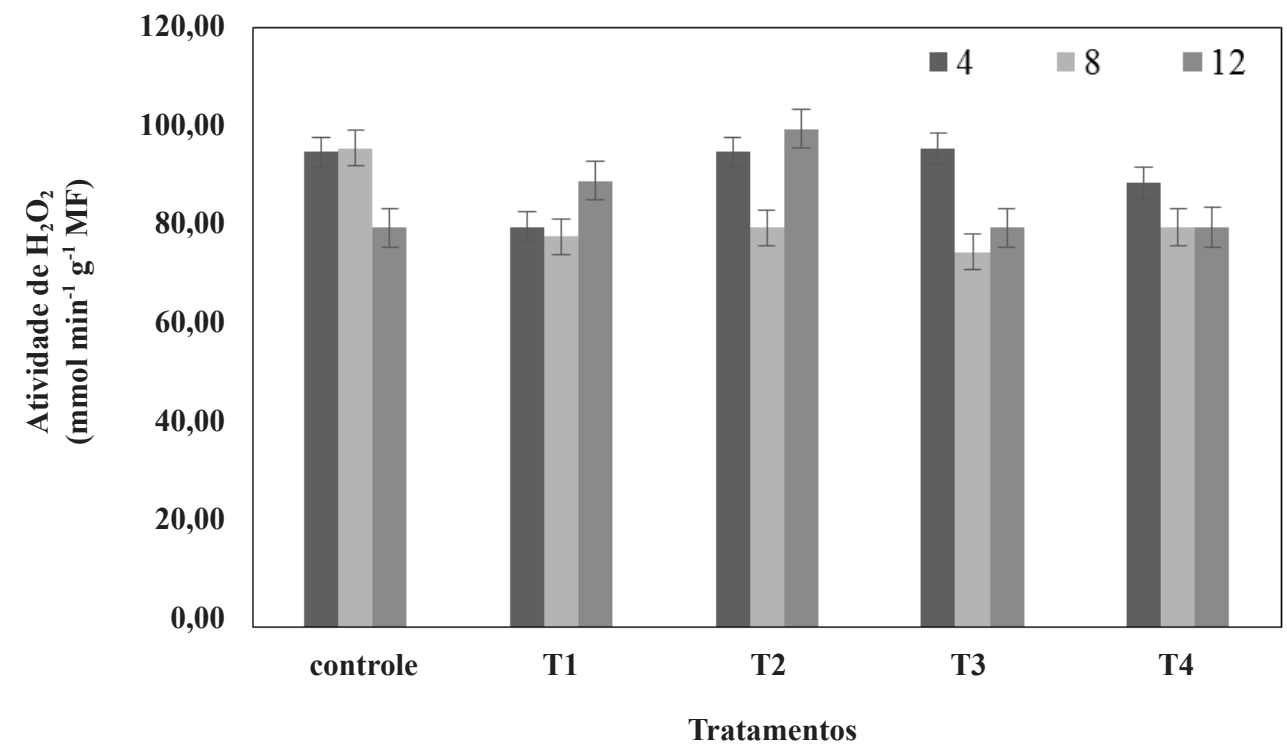

Figura 2. Atividade da catalase em folhas de feijão caupi, cultivar IPA 206, nos diferentes tempos (dias) de inoculação com Colletotrichum lindemuthianum URM 5771 e acibenzolar-S-metil. Tratamentos: T1 $\left(0,15 \mathrm{~g} \mathrm{~L}^{-1}\right)$; T $2\left(0,30 \mathrm{~g} \mathrm{~L}^{-1}\right)$; T $3\left(0,45 \mathrm{~g} \mathrm{~L}^{-1}\right)$, T $4\left(0,60 \mathrm{~g} \mathrm{~L}^{-1}\right)$ e controle (água destilada).

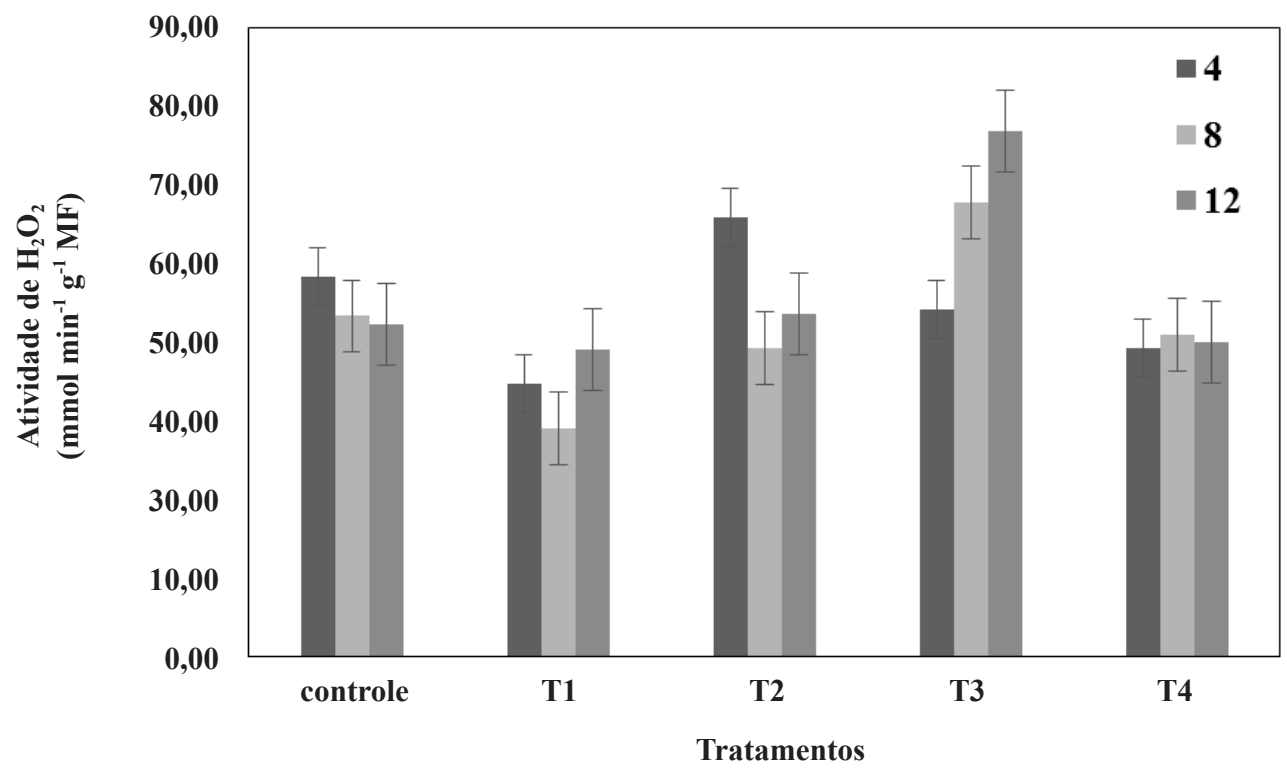

Figura 3. Atividade da polifenoloxidase em folhas de feijão caupi, cultivar IPA 206, nos diferentes tempos (dias) de inoculação com Colletotrichum lindemuthianum URM 5771 e acibenzolar-S-metil. Tratamentos: T1 $\left(0,15 \mathrm{~g} \mathrm{~L}^{-1}\right)$; T $2\left(0,30 \mathrm{~g} \mathrm{~L}^{-1}\right)$; T $3\left(0,45 \mathrm{~g} \mathrm{~L}^{-1}\right)$, T $4\left(0,60 \mathrm{~g} \mathrm{~L}^{-1}\right)$ e controle (água destilada). 


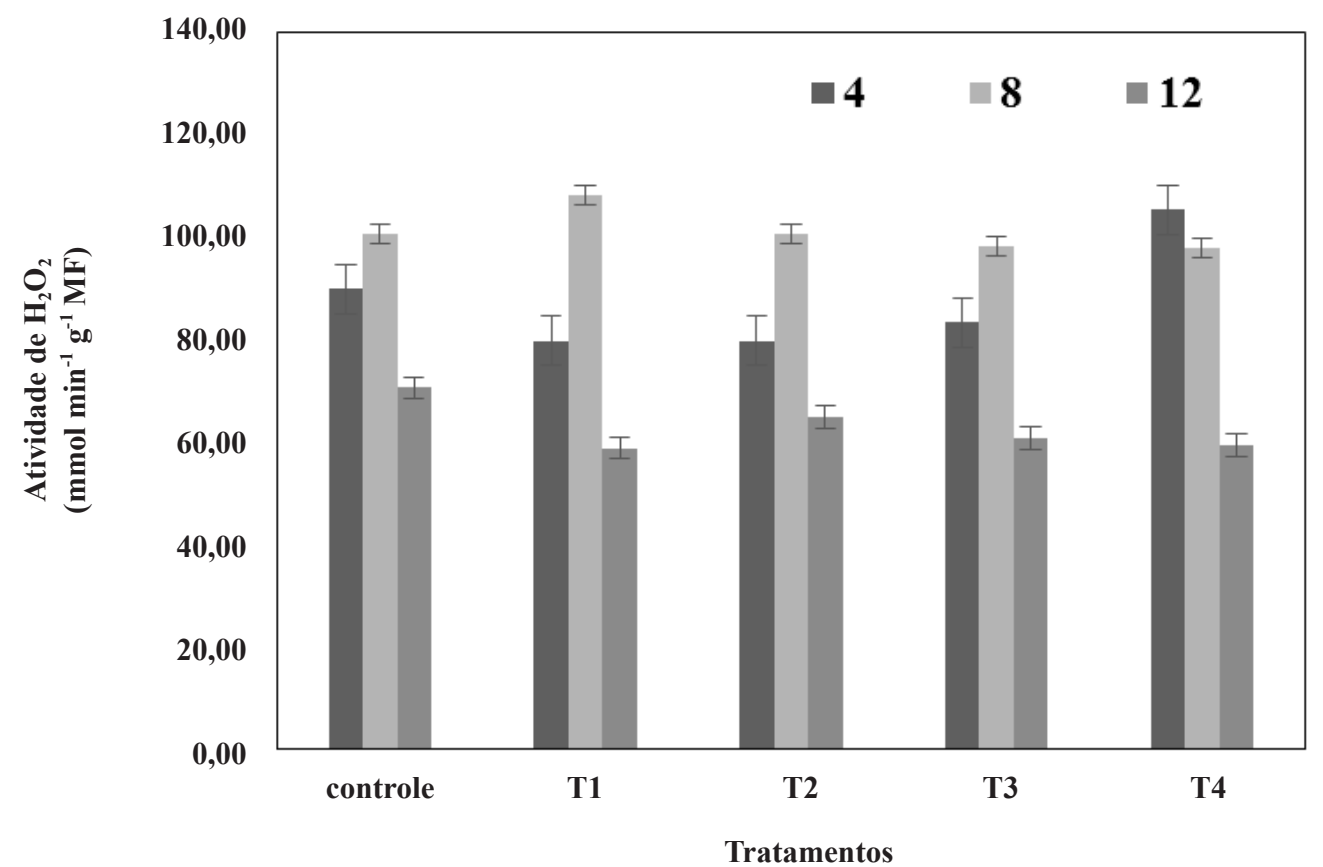

Figura 4. Atividade da ascorbato peroxidase em folhas de feijão caupi, cultivar IPA 206, nos diferentes tempos (dias) de inoculação com $C$. lindemuthianum URM 5771 e acibenzolar-S-metil. Tratamentos: T1 $\left(0,15 \mathrm{~g} \mathrm{~L}^{-1}\right)$; T $2\left(0,30 \mathrm{~g} \mathrm{~L}^{-1}\right)$; T $3\left(0,45 \mathrm{~g} \mathrm{~L}^{-1}\right)$, T $4\left(0,60 \mathrm{~g} \mathrm{~L}{ }^{-1}\right)$ e controle (água destilada).

uma proteção da planta contra o ataque de determinado patógeno.

Diante disso, pode-se analisar que alguns mecanismos de resistência são ativados após a inoculação das plantas com agentes patogênicos. Em plantas resistentes essa ativação de respostas de defesa é rápida, impedindo ou reduzindo a colonização, o que não ocorre em plantas susceptíveis, pois esse processo é lento. O tratamento prévio com indutores de resistência pode preparar plantas suscetíveis, por meio da ativação rápida de respostas de defesa, e assim reduzir a intensidade de doenças causadas por esses patógenos (16).

Observa-se resultados referentes a polifenoloxidase em folhas de feijão caupi cultivar IPA 206, o tratamento $2\left(0,30 \mathrm{~g} \mathrm{~L}^{-1}\right.$ de indutor) estimulou maior atividade enzimática e foi estatisticamente diferente dos demais, dados relacionados ao quarto dia. Enquanto que, no oitavo dia houve acréscimo da atividade enzimática nos tratamentos 3 e 4, respectivamente. No décimo segundo dia após da inoculação é notável o aumento da atividade de polifenoloxidase no tratamento $3\left(0,45 \mathrm{~g} \mathrm{~L}^{-1}\right)$.

Silva et al. (20) trabalharam com feijão comum e observaram que a aplicação de um indutor de resistência promoveu resposta mais rápida, em resposta à inoculação com Xanthomonas axonopodis, o que proporcionou aumento expressivo da atividade de polifenoloxidase e conduziu maior resistência às plantas. A importância da atividade da polifenoloxidase na resistência as doenças deve-se, provavelmente, à sua propriedade em oxidar compostos fenólicos em quinonas, os quais são muito mais tóxicos aos microrganismos do que o fenol original, e à sua ação protetora no local do ferimento. Por esta razão, admite-se que um aumento na atividade da polifenoloxidase resulta em altas concentrações de produtos tóxicos de oxidação e, portanto, maior grau de resistência à infecção (26).

Em trabalhos com indução de resistência em tomateiro utilizando
acibenzolar-S-metil Itako et al. (8) observaram que a aplicação desse indutor aumentou a atividade da polifenoloxidase em plantas de tomateiro, confirmando sua capacidade de induzir resistência em plantas cultivadas, evidenciando que este produto pode ter relação direta com a indução de resistência à antracnose em plantas de feijão caupi. Cavalcanti et al. (5) atribuíram o fato de que a atividade dessa enzima está correlacionada com a resistência induzida, sendo produzidas algumas horas após a pulverização em plantas e até 12 dias após.

A atividade de ascorbato peroxidase obtida em folhas de feijão caupi cultivar IPA 206 (Figura 4), demonstrou que no quarto dia o tratamento 4 contribuiu para a maior atividade enzimática,. Entretanto, no oitavo dia após a inoculação é notável o aumento da atividade nos tratamentos $1,2,3$, bem como no controle; e redução da atividade enzimática para o tratamento 4. No décimo segundo dia após a inoculação observa-se decréscimo na atividade enzimática em todos os tratamentos.

A ascorbato peroxidase é considerada umas das peroxidases mais importantes, pois catalisa a redução do $\mathrm{H}_{2} \mathrm{O}_{2}$, por meio do poder redutor do ascorbato. Leite et al. (11) trabalharam com resistência induzida em feijão comum e observaram que níveis elevados desta enzima são mais atuantes e constantes precocemente, podendo contribuir na resistência a antracnose, reduzindo os efeitos danosos produzidos por $C$. lindemuthianum. Segundo estudo realizado por Lanubile et al. (10) com milho, estes observaram que em plantas resistentes houve maior atividade de ascorbato peroxidase, podendo esta enzima está relacionada à prevenção da formação de $\mathrm{OH}^{-}$e efeitos tóxicos do acúmulo de $\mathrm{H}_{2} \mathrm{O}_{2}$.

A redução da atividade de ascorbato peroxidase no décimo segundo dia após a inoculação pode estar relacionada a potencialização reduzida do indutor após alguns dias decorrentes à inoculação ou até mesmo a baixa incidência do patógeno nesse período. Suza et al. (24) 
relataram que algumas espécies de plantas, após sofrerem algum tipo de lesão, apresentam uma queda na concentração de ácido ascórbico, que participa de reações de detoxificação, de forma enzimática e não enzimática de espécies reativas de oxigênio geradas pelo metabolismo celular aeróbico e por estresses bióticos e abióticos.

Pode-se inferir que os tratamentos com maiores doses do acibenzolar-S-metil proporcionam maior atividade enzimática e consequentemente maior resistência às plantas de feijão caupi (Vigna unguiculata) e redução da severidade dos sintomas da antracnose, visto que não houve potencial de dano.

\section{AGRADECIMENTOS}

Ao CNPq e a Capes pelo apoio financeiro e a concessão da bolsa de estudos.

\section{REFERÊNCIAS}

1. Andrade, C.C.L.; Resende, R.S.; Rodrigues, F.A.; Silveira, P.R.; Rios, J.A.; Oliveira, J.R.; Mariano, R.L.R. Indutores de resistência no controle da pinta bacteriana do tomateiro e na atividade de enzimas de defesa. Tropical Plant Pathology, Brasília, v. 38, n. 1, 2013. URL: http:/www.scielo.br/pdf/tpp/ v38n1/v38n1a04.pdf.

2.Antunes, I.F.; Santin, R.C.M.; Chollet, C.B.; Fernandes, R.A.M.L.; Campos, A.D.; Silveira, J.J.; Emygdio, M.B.M.; Rodrigues, L.S.; Brancão, L.S.R.N. Reação de cultivares crioulas de feijão do Rio Grande do Sul a isolados de Colletotrichum lindemunthianum, agente causal da antracnose. Revista Brasileira de Agroecologia, Pelotas, [S.1.], v.1, n.1, 2006. <http://aba-agroecologia.org.br/revistas/index.php/rbagroecologia/article/view/6070>. Acesso em: 29 ago. 2017.

3. Campos, A.D.; Hampe, M.M.V.; Ferreira, A. G.; Antunes, I. F.; Castro, L. A. S. Indução de resistência sistêmica à antracnose em feijoeiro-comum pela raça delta avirulenta de Colletotrichum lindemuthianum. Pesquisa Agropecuária Brasileira, Brasília, v.44, n.1, p.15-21, jan. 2009. http:// www.scielo.br/pdf/pab/v44n1/03.pdf.

4. Cavalcanti, F.R.; Resende, M.L.V.; Lima, J.P.M.S.; Silveira, J.A.G.; Oliveira, J.T.A. Activities of antioxidant and photosynthetic responses in tomato pre-treated by plant activator sand inoculated by Xanthomonas vesicatoria. Physiological and Molecular Plant Pathology, Amsterdã, v. 68, p.198-208, 2006. DOI: 10.1016/j.pmpp.2006.11.001.

5. Cavalcanti, L.S.; Brunelli, K.R.; Stangarlin, J.R. Aspectos bioquímicos e moleculares da resistência induzida. In: Cavalcanti, L.S.; Di Piero, R.M.; Cia, P.; Pascholati, S.F.; Resende, M.L.V.; Romeiro, R.S. Indução de Resistência em Plantas a Patógenos e Insetos. Piracicaba: FEALQ, 2005, p.81-124.

6. Deuner, C.; Maia, M.S.; Deuner, S.; Almeida, A.; Meneghello, G.E. Viabilidade e atividade antioxidante de sementes de genótipos de feijão-miúdo submetidos ao estresse salino. Revista Brasileira de Sementes, Londrina, v.33, n.4,p.711-720, 2011. URL: http://www.scielo.br/pdf/rbs/v33n4/13.pdf.

7. Furtado, L.M.; Rodrigues, A.A.C.; Araújo, V.S.; Silva, L.L.S.; Catarino,

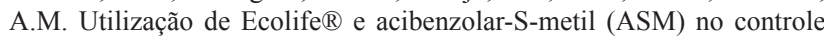
da antracnose da banana em pós-colheita. Summa Phytopathologica, Botacatu, v.36, n.3, p.237-239, 2010. URL: http:/www.scielo.br/pdf/sp/ v36n3/v36n3a09.pdf.

8. Itako, A.T.; Júnior, J.B.T.; Júnior, T.A.F. da. S.; Soman, J.;Maringoni, A.C. Efeito de produtos químicos sobre a mancha bacteriana (Xanthomonas perforans) e na ativação de proteínas relacionadas à patogênese em tomateiro. Idesia, Arica, v.30, n.2, 2012. URL: http://www.scielo.cl/pdf/idesia/ v30n2/art11.pdf.

9. Kar, M.; Mishra, D. Catalase, peroxidase, and polyphenoloxidase activities during rice leaf senescence. Plant Physiology, Bethesda, v.57, p.315-319, 1976. URL: https:/www.ncbi.nlm.nih.gov/pmc/articles/PMC542015/pdf/ plntphys00156-0193.pdf

10. Lanubile, A.; Bernardi, J.; Marocco, A.; Logrieco, A.; Paciolla, C. Differential activation of defense genes and enzymes in maize genotypes with contrasting levels of resistence to Fusarium verticillioides. Environmental and Experimental Botany, Barcelona, v.78, p.39-46, 2012. URL: http://ac.els-cdn.com/S0098847211003133/1-s2.0-S0098847211003133main.pdf?_tid $=$ a64e3c12-8d78-11e 7-8791-00000aab0f6c\&acdnat $=150409 \overline{3} 678$ a48cab6f65d2ff3e3209ccb813357b50. DOI: $10.1016 / \mathrm{j}$. envexpbot.2011. 12.006 .

11. Leite, M. de L.; Virgens Filho, J.S. Produção de matéria seca em plantas de caupi (Vigna unguiculata (L.) Walp) submetida a déficit hídrico. Ciências Exatas e da Terra, Ponta Grossa, v.10, p.43-51, 2004. DOI: http://dx.doi. org/10.5212/publicatio.v10i01.820

12. Lusso, M.F.G.; Pascholati, S.F. Activity and isoenzymatic pattern of soluble peroxidases in maize tissues after mechanical injury or fungal inoculation. In: Kuhn, O. J. Indução de resistência em feijoeiro (Phaseolus vulgaris) por acibenzolar-s-metil e Bacillus cereus: aspectos fisiológicos, bioquímicos e parâmetros de crescimento e produção. 2007. 140f. Tese. (Doutorado em Fitopatologia) - Esalq, Piracicaba.

13. Macagnan, D.; Romeiro, R.S.; Baracat-Pereira, M.C. Lanna-Filho, R.; Batista, G.S.; Pomella, A.W.V. Atividade de enzimas associadas ao estado de indução em mudas de cacaueiro expostas a dois actinomicetos residentes de filoplano. Summa Phytopathologica, Botucatu, v.34, n.1, p.34-37, 2008. http://www.scielo.br/pdf/sp/v34n1/a07v34n1.pdf

14. Marques Júnior, O.G.M.; Ramalho, M.A.P.; Ferreira, D.F.; Santos, J.B Viabilidade do emprego de notas na avaliação de alguns caracteres do feijoeiro (Phaseolus vulgaris L.). Revista Ceres, Viçosa, v.44, n.254, p. 411-420, 1997. URL: http://www.ceres.ufv.br/ojs/index.php/ceres/article/ view/2434/435.

15. Menezes, M. Aspectos biológicos e taxonômicos de espécies do gênero Colletotrichum. Anais da Academia Pernambucana de Ciência Agronômica, Recife, v.3, p.170-179, 2006. https://ainfo.cnptia.embrapa.br/digital/ bitstream/item/34611/1/AAPCA-V3-Revisao-04.pdf.

16. Planchamp, C.; Balmer, D.; Hund, A.; Mauch-mani, B.A Soil-free root observation system for the study of root-microorganism interactions in maize. Plant and Soil, Dordrecht, v.367, p.605-614, 2013. URL: https:// link.springer.com/content/pdf/10.1007\%2Fs11104-012-1497-8.pdf. DOI: 10.1007/s11104-012-1497-8.

17. Rava, C.A.; Molina, J.; Kauffmann, M.; Briones, I. Determinación de razas fisiológicas de Colletotrichum lindemuthianum em Nicaragua. Fitopatologia Brasileira, Brasília, v.18, p.388-391, 1993.

18. Resende, M.L.V.; Nojosa, G.B.A.; Cavalcanti, L.S.; AGUILAR, M.A.G.; SILVA, L.H.C.P.; PEREZ, J.O.; Andrade, G.C.G.; Carvalho, G.A.; Castro, R.M. Induction of resistance in cocoa against Crinipellis perniciosa and Verticillium dahliae by acibenzolar-S-methyl (ASM). Plant Pathology, London, v.51, p.621-628, 2002. URL: http://onlinelibrary.wiley.com/ doi/10.1046/j.1365-3059.2002.00754.x/epdf.

19. Salgado, F.H.M.; Silva, J.; Oliveira, T.C.; Barros, H.B.; Passos, N.G.; Fidelis, R.B. Eficiência de genótipos de feijoeiro em resposta à adubação nitrogenada. Pesquisa Agropecuária Tropical, Goiânia, v.42, n.4, p.368-374, 2012. URL: http://www.scielo.br/pdf/pat/v42n4/v42n4a07.pdf.

20. Silva E.G.; Moura A.B.; Bacarin, M.A.; Deuner, C.C. Metabolic alterations on bean plants originated from microbiolization of seeds with Pseudomonas sp. and inoculated with Xanthomnas axonopodis pv. phaseoli. Summa Phytopathologica, v.35, n.2, p.98-104, 2009. URL: http:/www.scielo.br/ $\mathrm{pdf} / \mathrm{sp} / \mathrm{v} 35 \mathrm{n} 2 / \mathrm{v} 35 \mathrm{n} 2 \mathrm{a} 03 . \mathrm{pdf}$.

21. Silva, I.T.; Rodrigues, F.Á.; Oliveira, J.R.; Pereira, S.C.; Andrade, C.C.L.; Silveira, P.R.; Conceição, M.M. Wheat resistance to bacterial leaf streak mediated by silicon. Journal of Phytopathology, Berlin, v.158, n.4, p.253-262, 2010. URL: http://onlinelibrary.wiley.com/doi/10.1111/j.14390434.2009.01610.x/epdf.

22. Silva, R.P.; Cassia, M.T.; Voltarelli, M.A.; Compagnon, A.M.; Furlani, C.E.A. Qualidade da colheita mecanizada de feijão (Phaseolus vulgaris) em dois sistemas de preparo do solo. Ciência Agronômica, Fortaleza, v.44, n.1, p.61-69, 2013. URL: http://www.ccarevista.ufc.br/seer/index. $\mathrm{php} /$ ccarevista/article/view/1936/773.

23. Soylu, E.M.; Baysal, O.; Soylu, S. Induction of defense-related enzymes and resistance by the plant activator acibenzolar-S-methyl tomato seedlings against bacterial canker caused by Clavibacter michiganensis subsp michiganensis. Plant Pathology, London, v. 52, p.747-753, 2003. http:/ data2.xjlas.ac.cn:81/UploadFiles/sdz/cnki/\%E5\%A4\%96\%E6\%96\%87/ ELSEVIER/stress\%20resistance/46.pdf

24. Suza, W.P.; Avila, C.A.; Carruthers, K.; Kulkarni, S; Goggin, F.L.; Lorence, 
A. Exploring the impact of wounding and jasmonates on ascorbate metabolism. Plant Physiology and Biochemistry, Paris, v.48, p.337-350, 2010. URL: https://www.ncbi.nlm.nih.gov/pmc/articles/PMC2880922/.

25. Valente, T.C.T. Expressão gênica e atividade de catalase e fenilalanina amônia liase ativadas por indutores de resistência em cafeeiro. 2012. 67f. Dissertação (Mestrado em Biotecnologia Vegetal) - UFLA, Lavras. URL: http://repositorio.ufla.br/bitstream/1/831/1/DISSERTAÇÃO_Expressão $\% 20$ gênica $\% 20 \mathrm{e} \% 20$ atividade $\% 20 \mathrm{de} \% 20$ catalase $\% 20 \mathrm{e}^{-} \% 20$ fenilalanina $\% 20$ amonia $\% 20$ liase $\% 20$ ativadas $\% 20$ por $\% 20$ indutores $\% 20$ de\%20resistência\%20em\%20cafeeiro.pdf.

26. Zheng, C.; Teng, B.; Gao, F.; Wu, Z.; Zheng, C,M.; Teng, B.; Gao, F.L.; $\mathrm{Wu}, \mathrm{Z}$. Studies on the changes of superoxido dismutase, peroxidase and poliphenol oxidase in seed coat of soybeans after infection with soybean mosaic virus. Scientia-Agricultura Sinica, Beijing,v.32, p.99-101, 1999.
URL: https://www.cabdirect.org/cabdirect/abstract/19991003667

27. Bianchini, A.; Maringoni, A. C.; Carneiro, S. M. T. P. G. Doenças do Feijoeiro. In: Kimati, H.; Amorin, L.; BergaminFilho, A.; Camargo, L. E. A.; Rezende, J. A. M. Manual de Fitopatologia: Doenças das Plantas Cultivadas. 4. Ed. São Paulo: Agronômica Ceres, 2005. v. 2, p. 333-349.

28. Oliveira, J.T.A., Andrade, N.C., Miranda, A.S.M., Barreto, A.L.H., Melo, V.M.M., Fernandes, C.F., Vasconcelos, I.M., Silveira, J.A.G., Cavalcanti, F.R., Freire-Filho, F.R., Freire, F.C.O. \& Gonçalves, F.J.T. Atividades peroxidásica e $\beta-1,3$ glucanásica elicitadas por agentes bióticos causadores de doenças e pelo estresse hídrico em feijão-de corda [Vigna unguiculata $(\mathrm{L}$. Walp.]. Anais: V Reunião Nacional de pesquisa de Caupi-V RENAC, Teresina, PE. 2001. pp. 19-23.

29. Durrant, W.E. \& Dong, X. Systemic acquired resistance. Annual Review of Phytopathology 42:185-209. 2004. 